\title{
Identifikasi Kekuatan Batu Kumbung (Batu Putih) Sebagai Salah Satu Alternatif Bahan Bangunan
}

\author{
Moh Muntaha \\ Dosen D3 Teknik Sipil FTSP-ITS \\ email:mohamad_m74@ce.its.ac.id
}

\begin{abstract}
ABSTRAK
Meningkatnya kebutuhan rumah sebagai tempat tinggal menyebabkan semakin bertambahnya jumlah pemakaian bahan bangunan. Hal ini mengakibatkan semakin bervariasinya bahan bangunan yang digunakan untuk memenuhi kebutuhan tersebut, seperti batako, paving stone, batu pecah, batu bata, dan batu kumbung (batu putih). Disamping itu, pemakaian bahan bangunan di suatu daerah umumnya dipengaruhi oleh kondisi daerah tersebut. Misalnya di daerah Bangkalan, Gresik, Tuban, Bojonegoro dan Lamongan karena daerah ini banyak terdapat gunung kapur, maka batu gunung ini yang disebut batu kumbung banyak dipakai sebagai bahan bangunan. Metode penelitian dalam studi ini adalah studi teoritis mengenai identifikasi parameter dasar dan kekuatan batuan berdasarkan ketentuan yang ada di Standar Nasional Indonesia (SNI) meliputi berat jenis, kadar air, porositas dan kuat tekan uniaksial batuan. Sedangkan benda uji berupa batu kumbung (batu putih) diambil dari 2 daerah yang mewakili yaitu daerah Bangkalan dan Lamongan. Dari hasil studi menunjukkan, batu kumbung Lamongan dan Bangkalan mempunyai parameter dasar (berat jenis, kadar air, porositas) yang hampir sama yaitu berat jenis berkisar antara $1.8 \mathrm{gr} / \mathrm{cm}^{3}$, kadar air 0,24\% dan porositas 0,4 . Sedangkan kuat tekan uniaksial batu kumbung (batu putih) Lamongan rata-rata $32.5 \mathrm{~kg} / \mathrm{cm}^{2}$, untuk batu kumbung (batu putih) Bangkalan adalah rata-rata $22.5 \mathrm{~kg} / \mathrm{cm}^{2}$. Mempunyai kekuatan yang lebih tinggi dibandingkan kuat tekan uniaksial batu bata yaitu $11.2 \mathrm{~kg} / \mathrm{cm}^{2}$, dan kuat tekan uniaksial batako yaitu $21.2 \mathrm{~kg} / \mathrm{cm}^{2}$. akan tetapi lebih rendah dibandingkan kuat tekan batu pecah (batu belah)
\end{abstract}

Kata kunci: Batu Kumbung, berat jenis, Kuat Tekan

\section{PENDAHULUAN}

Pemakaian bahan bangunan di suatu daerah umumnya dipengaruhi oleh kondisi daerah tersebut. Daerah Bangkalan, Tuban, dan Lamongan merupakan daerah yang banyak terdapat pegunungan kapur, maka di daerah ini batu dari gunung-gungung ini yang disebut batu kumbung (batu putih) banyak digunakan sebagai bahan bangunan. Di samping di kedua daerah tersebut batu kumbung banyak terdapat di Kabupaten Tuban, Kabupaten Gresik, Kabupaten Pamekasan dan Kabupaten Bangkalan. Didaerah ini batu kumbung banyak dimanfaatkan sebagai bahan bangunan yaitu sebagai dinding pengganti batu bata dan sebagai pondasi rumah. Gambar 1 di bawah menunjukkan pemakaian batu kumbung sebagai bahan dinding pengganti batu bata.
Batu kumbung ini dipilih untuk diteliti karena sudah banyak dimanfaatkan sebagai bahan bangunan di daerah-daerah tersebut, namun belum banyak diketahui atau diteliti kualitasnya baik parameter-parameter dasarnya maupun kekuatannya.

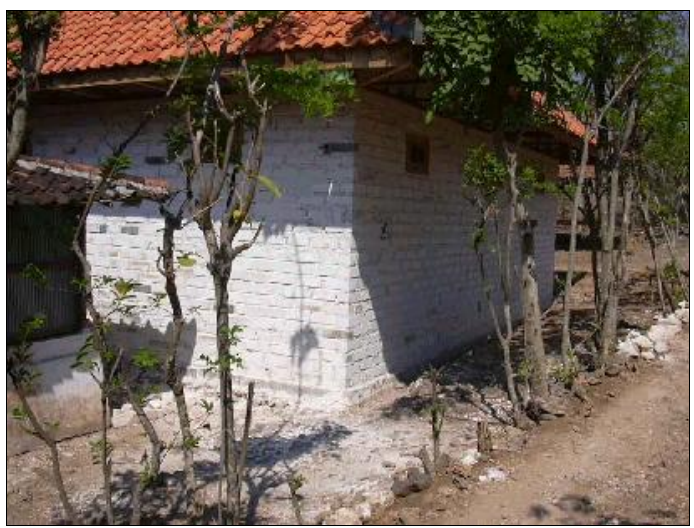

Gambar 1. Batu kumbung untuk Dinding 


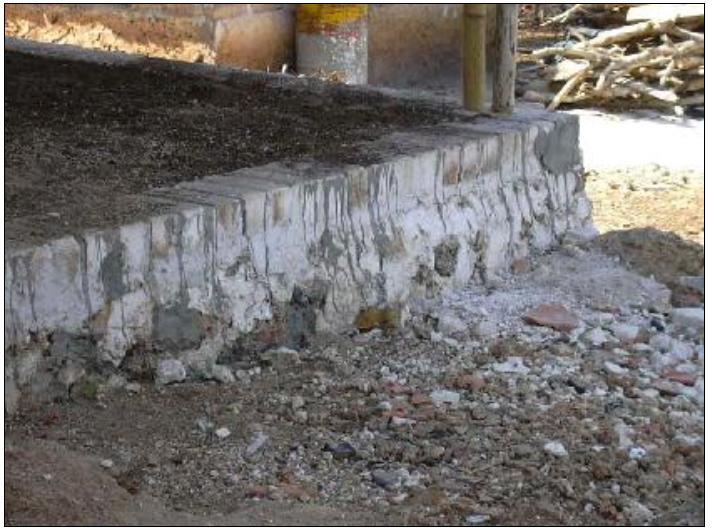

Gambar 2. Batu Kumbung untuk Pondasi

Pada penelitian ini akan diteliti bagaimana parameter dasar, kekuatan batuan berdasarkan ketentuan yang ada di Standar Nasional Indonesia (SNI) meliputi berat jenis, kadar air, porositas dan kuat tekan uniaksial batuan serta simulasi penggunaan batu kumbung (batu putih) sebagai pondasi dan dinding pada rumah jika dibandingkan dengan menggunakan bahan bangunan yang lain yaitu batu pecah, batu bata, batako.

\section{TINJAUAN PUSTAKA}

Pada penelitian ini yang didefinisikan sebagai bahan bangunan adalah bahan bangunan yang umum dipakai sebagai dinding atau pondasi rumah sederhana. Ada 2 (dua) jenis bahan bangunan yaitu bahan bangunan yang didapat langsung dari alam seperti : batu pecah, kerikil, pasir, batu kumbung, dan bahan bangunan yang dibuat oleh manusia seperti : batu bata, batako, genting, batu beton, dan lain sebagainya. Pada pemakaian yang umum, baik bahan bangunan yang di dapat langsung dari alam maupun bahan bangunan buatan, akan direkatkan satu sama lain dengan perekat (spesi). Perekat tersebut bervariasi tergantung pada kegunaannya. Sebagai contoh : perekat untuk pondasi batu pecah adalah campuran semen, pasir dan kapur, perekat untuk dinding bagian bawah yang fungsinya untuk mencegah peresapan air tanah ke dinding adalah campuran semen dan pasir. Komposisi berat bahan perekat juga bervariasi, misalnya : 1 bagian semen, 2 bagian pasir dan 3 bagian kapur, atau 1 bagian semen dan 2 bagian pasir (hanya untuk pondasi dan dinding).

\subsection{Klasifikasi Batuan}

Batuan beku berasal dari magma yang berada di pusat bumi dan kemudian keluar ke arah permukaan bumi. Karena adanya pergerakan bumi, sebagian batuan yang berada di bawah akan berpindah ke permukaan bumi.

Karena pengaruh cuaca, batuan beku akan melapuk dan kemudian karena aliran angin dan air akan tersedimentasi dan menjadi batuan sedimen. Batuan sedimen bisa berubah sifat-sifat mineralnya karena tekanan dan panas bumi sehingga menjadi batuan metamorf.

Batu putih pada dasarnya adalah batuan sedimen dari batu kapur. Kandungan mineral batuan sedimen kapur adalah sekitar $95 \%$ Calcite, 3 \% Dolomite dan $2 \%$ Mineral lempung. Tegangan runtuh batuan sedimen kapur bervariasi dari 20 - $100 \mathrm{Mpa}$, dan kekuatan menahan beban berkisar antara 0,5 - 4 Mpa.

Batu pecah pada dasarnya adalah batuan beku. Kandungan mineral batuan beku adalah sekitar $25 \%$ Quartz, 50 \% Feldspar, $15 \%$ Mica dan $10 \%$ Mafics.

Tegangan runtuh berkisar $200 \mathrm{Mpa}$ sedangkan kekuatan menahan beban berkisar $10 \mathrm{Mpa}$.

Proses geologi untuk pembentukan batuan bisa digambarkan pada Gambar 3 di bawah ini

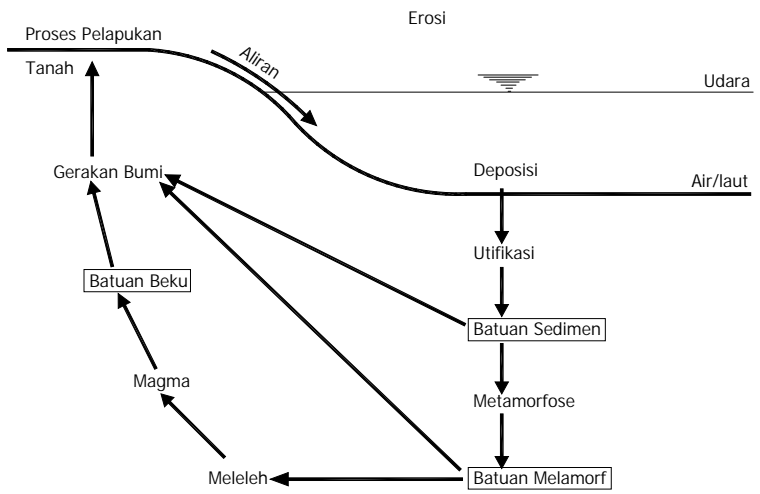

Gambar 3. Proses Geologi Pembentukan batuan 


\subsection{Kekuatan Bahan Bangunan}

Kekuatan bahan bangunan bervariasi tergantung kepada bahan dan mineral pembentuknya. Bahan Bangunan ada yang bersifat bentukan alam proses kimiawi tambahan seperti batu pecah, batu putih dan sebagainya, dan ada yang bersifat bentukan alam dengan proses pembakaran seperti genting, bata merah dan lain-lain. Selain itu bahan bangunan ada yang bersifat bahan tambang dengan proses kimiawi seperti aluminium, besi dan lain-lain. Pada penelitian ini yang diulas hanya bahan bangunan yang bersifat alam saja. Bahan bangunan yang diteliti dianggap tidak mempunyai kekuatan menahan lentur yang sangat kecil. Sebelum dilakukan pengujian kekuatan, batuan diperiksa parameter dasarnya. Pengujian parameter dasar yang umum dilakukan adalah pengujian : berat jenis, kepadatan dan penyerapan air (SNI 03-2437 - 1991).

Pengujian kekuatan batuan yang paling umum dilakukan adalah pengujian kuat tekan iniaksial batuan (SNI 03-2825 - 1992). Pengujian lain yang perlu dilakukan adalah : Pengujian geser langsung batu (SNI 03-28241992), Pengujian modulus elastisitas batu pada tekanan sumbu tunggal (SNI 03-28261992), Pengujian laboratorium kuat tarik dengan cara tidak langsung (SNI 03-24861991) dan pengujian kuat lentur batu pemakai gelagar sederhana dengan sistem beban titik di tengah (SNI 03-2823 - 1992).

\subsection{Gambaran Umum Batu Kumbung}

Obyek studi penelitian ini adalah batu kumbung (batu putih) dari Kabupaten Lamongan dan Kabupaten Bangkalan. Batu kumbung diambil dari pusat penambangan di mana batuan dasarnya adalah batuan gamping. Pusat penambangan di Kabupaten Lamongan terletak di sebelah barat di dekat perbatasan Kabupaten Lamongan dan Kabupaten Bojonegoro. Sedangkan pusat penambangan di Kabupaten Bangkalan terletak di sebelah selatan di dekat kaki jembatan Suramadu. Batu kumbung yang digunakan sebagai dinding pada umumnya mempunyai ukuran $\pm 20 \times 10 \times 8 \mathrm{~cm} 3$, sedangkan yang digunakan sebagai pondasi rumah pada umumnya mempunyai ukuran \pm $30 \times 30 \times 30 \mathrm{~cm} 3$.

\section{METODOLOGI}

Studi teoritis mengenai identifikasi parameter dasar dan kekuatan batuan dipelajari dari ketentuan yang ada di Standar Nasional Indonesia. Studi lapangan dilakukan di lokasi penambangan batu kumbung di Kabupaten Lamongan dan Kabupaten Bangkalan. Batu kumbung yang akan diteliti didapatkan dari Kabupaten Lamongan dan Kabupaten Bangkalan, sedangkan batu bata, batako dan batu pecah dibeli dari Surabaya.

Pengujian laboratorium dikerjakan di laboratorium Mekanika Tanah dan Batuan Jurusan Teknik Sipil ITS.

Pengujian laboratorium untuk menentukan parameter dasar dan kekuatan menahan beban yang akan dilakukan adalah :

- Identifikasi batuan : berat jenis, kadar air, porositas

- Identifikasi kekuatan: kuat tekan uniaksial batuan

Alur pikir Penelitian disimpulkan pada Gambar 4 berikut ini.

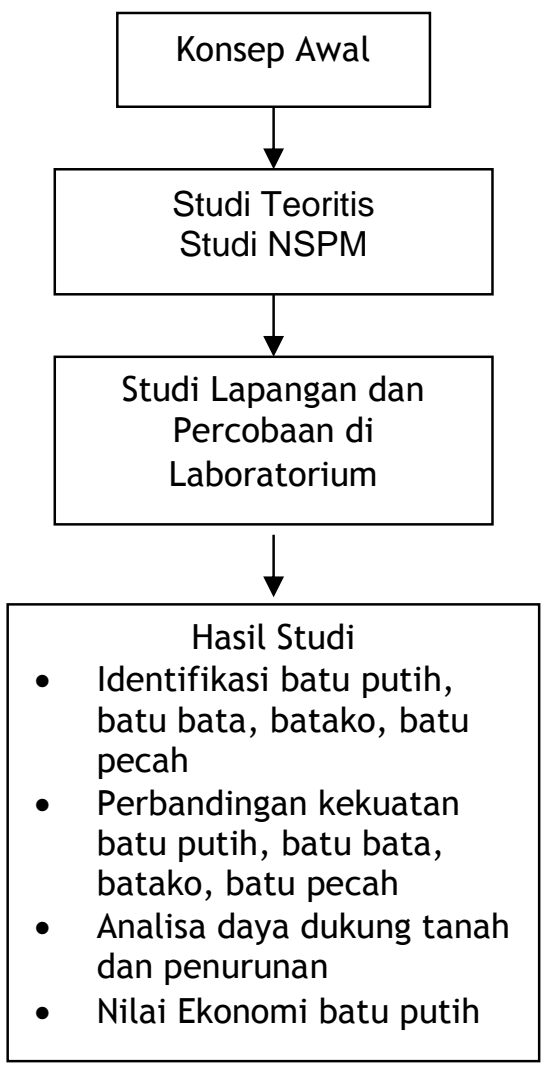

Gambar 4 Metode Penelitian 


\section{HASIL PENILITIAN}

4.1. Pengujian Parameter Dasar Batuan. Pengujian parameter dasar batuan adalah pengujian kepadatan natural, kadar air natural, derajat kejenuhan, porositas dan kadar pori. Pengujian dilakukan menurut SNI 03-2437-1991.

Hasil pengujian menunjukkan Batu kumbung Lamongan dan Bangkalan mempunyai parameter dasar (kepadatan, berat jenis, kadar air, derajat kejenuhan, porositas dan kadar pori) yang hampir sama yaitu kepadatan natural berkisar antara 1.78 $\mathrm{gr} / \mathrm{cm}^{3}$, lebih tinggi dari batu bata merah $1.58 \mathrm{gr} / \mathrm{cm}^{3}$ akan tetapi lebih rendah dibandungkan batu pecah (batu vulkanik) $1.96 \mathrm{gr} / \mathrm{cm}^{3}$.

Kadar air natural berkisar antara $0.24 \%$, hampir sama dengan batu bata merah dan batako tetapi lebuh tinggi dibandingkan batu pecah $0.19 \%$.

Derajat kejenuhan berkisar antara $1.2 \%$, hampir sama dengan batu bata merah, batako dan batu pecah.

Kadar pori berkisar antara 0.5 lebih rendah dibandingkan batu bata merah dan batako, tetapi lebih tinggi dibandingkan batu pecah. Selengkapnya hasil uji parameter dasar batuan dapat dilihat pada tabel 1 .

Tabel 1. Hasil Uji Parameter dasar batuan

\begin{tabular}{|c|c|c|c|c|c|c|c|c|c|c|c|}
\hline JENIS BATUAN & $\begin{array}{c}\text { Berat } \\
\text { Jenuh } \\
\text { Dalam Air } \\
\end{array}$ & $\begin{array}{c}\text { Kepadatan } \\
\text { Natural } \\
(\mathrm{gr} / \mathrm{cm} 3) \\
\end{array}$ & $\begin{array}{c}\text { Kepadatan } \\
\text { kering } \\
(\mathrm{gr} / \mathrm{cm} 3) \\
\end{array}$ & $\begin{array}{c}\text { Kepadatan } \\
\text { jenuh } \\
(\mathrm{gr} / \mathrm{cm} 3) \\
\end{array}$ & $\begin{array}{c}\text { Berat Jenis } \\
\text { Semu } \\
(\mathrm{gr} / \mathrm{cm} 3) \\
\end{array}$ & \begin{tabular}{|l|} 
Berat Jenis \\
Sebenarny \\
a (gr/cm3)
\end{tabular} & \begin{tabular}{|c|}
$\begin{array}{c}\text { Kadar Air } \\
\text { Natural } \\
(\%)\end{array}$ \\
\end{tabular} & $\begin{array}{l}\text { Kadar } \\
\text { Air } \\
\text { Jenuh } \\
\end{array}$ & \begin{tabular}{c|} 
Derajat \\
Kejenuhan \\
$(\%)$
\end{tabular} & Porositas & $\begin{array}{c}\text { Kadar } \\
\text { Pori }\end{array}$ \\
\hline Batu Kumbung Lamongan & & & & & & & & & & & \\
\hline 2 & $\begin{array}{l}103.100 \\
110.000\end{array}$ & $\begin{array}{l}1.774 \\
1.809\end{array}$ & $\begin{array}{l}1.770 \\
1.808\end{array}$ & $\begin{array}{l}1.104 \\
1.099\end{array}$ & $\begin{array}{l}1.770 \\
1.808\end{array}$ & $\begin{array}{l}2.658 \\
2.549\end{array}$ & $\begin{array}{l}0.240 \\
0.060\end{array}$ & $\begin{array}{l}18.87 \\
16.08\end{array}$ & $\begin{array}{l}1.28 \\
0.34\end{array}$ & $\begin{array}{l}0.428 \\
0.100\end{array}$ & $\begin{array}{l}0.749 \\
0.111\end{array}$ \\
\hline & 101.300 & 1.765 & 1.761 & 1.073 & 1.761 & 2.561 & 0.240 & 17.75 & 1.36 & 0.424 & 0.735 \\
\hline Average & 104.800 & 1.783 & 1.780 & 1.092 & 1.780 & 2.589 & 0.180 & 17.57 & 0.99 & 0.317 & 0.532 \\
\hline \multirow{2}{*}{ Batu Kumbung Bangkalan } & & & & & & & & & & & \\
\hline & 44.600 & 1.695 & 1.691 & 1.010 & 1.691 & 2.483 & 0.240 & 18.87 & 1.28 & 0.409 & 0.692 \\
\hline & 45.100 & 1.556 & 1.553 & 1.836 & 1.553 & 2.166 & 0.200 & 18.24 & 1.10 & 0.311 & 0.452 \\
\hline 3 & 41.900 & 1.734 & 1.730 & 1.037 & 1.730 & 2.497 & 0.240 & 17.75 & 1.36 & 0.416 & 0.713 \\
\hline Average & 43.900 & 1.662 & 1.658 & 1.961 & 1.658 & 2.382 & 0.230 & 18.29 & 1.25 & 0.379 & 0.619 \\
\hline Batu Bata Merah & & & & & & & & & & & \\
\hline 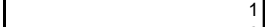 & 72.700 & 1.562 & 1.560 & 1.853 & 1.560 & 2.206 & 0.150 & 18.77 & 0.80 & 0.234 & 0.306 \\
\hline 2 & 52.800 & 1.615 & 1.610 & 1.914 & 1.610 & 2.313 & 0.300 & 18.86 & 1.60 & 0.485 & 0.94 \\
\hline 3 & 58.000 & 1.562 & 1.559 & 1.853 & 1.559 & 2.208 & 0.240 & 18.87 & 1.28 & 0.377 & 0.606 \\
\hline Average & 61.200 & 1.580 & 1.576 & 1.873 & 1.576 & 2.242 & 0.230 & 18.83 & 1.23 & 0.365 & 0.617 \\
\hline Batu Vulkanik & & & & & & & & & & & \\
\hline & 77.000 & 1.950 & 1.946 & 1.262 & 1.946 & 2.846 & 0.200 & 16.25 & 1.23 & 0.390 & 0.639 \\
\hline & 90.378 & 1.989 & 1.986 & 1.308 & 1.986 & 2.928 & 0.170 & 16.20 & 1.05 & 0.338 & 0.511 \\
\hline Average & 84.100 & 1.970 & 1.966 & 1.285 & 1.966 & 2.887 & 0.190 & 16.22 & 1.14 & 0.364 & 0.575 \\
\hline \multirow{5}{*}{ Batako } & & & & & & & & & & & \\
\hline & 53.530 & 1.789 & 1.784 & 1.102 & 1.784 & 2.615 & 0.250 & 17.79 & 1.41 & 0.447 & 0.809 \\
\hline & 73.970 & 1.812 & 1.806 & 1.120 & 1.806 & 2.630 & 0.290 & 17.34 & 1.68 & 0.525 & 1.107 \\
\hline & 52.900 & 1.805 & 1.801 & 1.116 & 1.801 & 2.628 & 0.250 & 17.49 & 1.43 & 0.451 & 0.822 \\
\hline & 60.100 & 1.802 & 1.797 & 1.112 & 1.797 & 2.624 & 0.260 & 17.54 & 1.51 & 0.475 & 0.913 \\
\hline
\end{tabular}

\subsection{Pengujian Kekuatan Batuan}

Batu kumbung dari Lamongan dan Bangkalan serta bahan-bahan yang lain seperti batu bata merah, batako, batu pecah (batu vulknik) diuji kekutan. Pengujian kekuatan batuan-batuan tersebut meliputi :

- Pengujian kuat tekan uniaksial batu (SNI M-10-1991-03)

- Pengujian kuat tarik benda uji batu dengan cara tidak langsung (SNI 03-24861991)

- Pengujian geser langsung batu (SNI M-091991-03)

- Pengujian indek kekuatan batu dengan beban titik (SNI M-109-1990-03)

Hasil-hasil pengujian kekuatan batu kumbung dan bahan bangunan yang lain yang di uji di laboratorium dapat dilihat pada tabel rekapitulasi pengujian kekuatan batuan yaitu pada tabel 2 dan tabel 3 Kekuatan yang dianggap mewakili. Dari tabel 3 terlihat kuat tekan uniaksial batu kumbung (batu putih) Lamongan rata-rata $32.5 \mathrm{~kg} / \mathrm{cm}^{2}$, untuk batu kumbung (batu putih) Bangkalan adalah rata-rata 22.5 $\mathrm{kg} / \mathrm{cm}^{2}$. Mempunyai kekuatan yang lebih tinggi dibandingkan kuat tekan uniaksial batu bata yaitu $11.2 \mathrm{~kg} / \mathrm{cm}^{2}$, dan kuat tekan uniaksial batako yaitu $21.2 \mathrm{~kg} / \mathrm{cm}^{2}$. 
Tabel 2 Rekapitulasi Hasil Uji Kuat Batu

\begin{tabular}{|c|c|c|c|c|c|c|c|c|c|c|}
\hline \multirow[b]{2}{*}{ JENIS BATUAN } & \multicolumn{3}{|c|}{ KUAT TEKAN UNIAKSIAL BATU } & \multicolumn{2}{|c|}{$\begin{array}{l}\text { KUAT TARIK BENDA } \\
\text { UJI BATU }\end{array}$} & \multicolumn{2}{|c|}{ KUAT GESER } & \multicolumn{3}{|c|}{$\begin{array}{c}\text { INDEK KEKUATAN BATU } \\
\text { DENGAN BEBAN TITIK }\end{array}$} \\
\hline & $\begin{array}{c}\text { Tegangan } \\
\text { Deviator } \\
\text { Puncak }(\mathrm{kg})\end{array}$ & $\begin{array}{c}\text { Modulus } \\
\text { Elastisitas } \\
(\mathrm{Kg})\end{array}$ & $\begin{array}{l}\text { Regangan } \\
\text { (cm) }\end{array}$ & $\begin{array}{c}\text { Beban } \\
\text { Maksimum } \\
(\mathrm{kg})\end{array}$ & \begin{tabular}{|c|} 
Tegangan \\
Tarik \\
Maksimum
\end{tabular} & $\begin{array}{c}\text { Beban } \\
\text { Maksimum } \\
(\mathrm{kg})\end{array}$ & $\begin{array}{c}\text { Tegangan } \\
\text { Geser } \\
\text { Maksimum }\end{array}$ & $\begin{array}{c}\text { Beban } \\
\text { Maksimum } \\
(\mathrm{kg})\end{array}$ & $\begin{array}{l}\text { Indek } \\
\text { Kekuatan } \\
\text { Beban }\end{array}$ & $\begin{array}{l}\text { Kekuatan } \\
\text { Tekan }(\mathrm{Kg})\end{array}$ \\
\hline \multicolumn{11}{|c|}{ Batu Kumbung Lamongan } \\
\hline Test ke - 1 & 41.300 & $2,609.890$ & 1.600 & 192.200 & 4.320 & 150.700 & 4.200 & 71.600 & 2.980 & 67.450 \\
\hline Test ke - 2 & 40.240 & $2,034.170$ & 1.800 & 214.800 & 4.830 & 241.200 & 6.390 & 113.050 & 4.910 & 110.100 \\
\hline Test ke - 3 & 18.760 & $1,594.700$ & 1.200 & 98.000 & 2.200 & 542.600 & 14.390 & 52.940 & 2.200 & 49.870 \\
\hline Test ke -4 & 7.900 & 671.450 & 1.200 & 226.100 & 3.880 & 640.600 & 17.700 & 94.890 & 4.120 & 92.420 \\
\hline Test ke -5 & 28.430 & $1,794.860$ & 1.800 & 282.600 & 4.530 & 602.900 & 16.250 & 164.800 & 7.150 & 160.510 \\
\hline \multicolumn{11}{|c|}{ Batu Kumbung Bangkalan } \\
\hline Test ke -1 & 19.490 & 311.760 & 5.800 & 499.400 & 6.870 & 209.000 & 5.540 & 29.960 & 1.250 & 28.230 \\
\hline Test ke -2 & 25.160 & 335.510 & 7.100 & 559.300 & 7.570 & 169.000 & 4.480 & 74.910 & 3.120 & 70.570 \\
\hline Test ke - 3 & 21.070 & 309.870 & 6.600 & 209.700 & 2.810 & 75.000 & 1.990 & 14.980 & 0.620 & 14.110 \\
\hline Test ke -4 & 27.290 & 284.730 & 8.300 & 279.700 & 3.910 & 175.000 & 4.640 & 48.940 & 2.040 & 46.110 \\
\hline Test ke - 5 & 15.280 & 287.980 & 4.900 & 224.700 & 2.920 & 200.000 & 5.300 & 15.980 & 0.670 & 15.060 \\
\hline \multicolumn{11}{|l|}{ Batu Bata Merah } \\
\hline Test ke -1 & 1.340 & 344.580 & 0.400 & 159.800 & 1.980 & 159.800 & 4.070 & 49.940 & 2.000 & 45.550 \\
\hline Test ke - 2 & 10.490 & 262.310 & 3.800 & 154.800 & 1.770 & 209.700 & 5.130 & 24.970 & 1.000 & 22.770 \\
\hline Test ke - 3 & 11.200 & 310.890 & 4.100 & 179.800 & 2.290 & 154.800 & 4.100 & 69.920 & 2.800 & 63.760 \\
\hline Test ke -4 & 11.370 & 187.640 & 6.300 & 168.800 & 2.130 & 154.800 & 4.100 & 65.920 & 2.640 & 60.120 \\
\hline Test ke -5 & 12.780 & 268.860 & 5.300 & 174.800 & 2.230 & 189.800 & 5.470 & 44.950 & 1.830 & 41.660 \\
\hline \multicolumn{11}{|l|}{ Batu Vulkanik } \\
\hline Test ke -1 & 167.950 & $4,261.500$ & 2.700 & $1,320.000$ & 28.910 & $1,200.000$ & 21.220 & 750.000 & 22.290 & 540.430 \\
\hline Test ke - 2 & 183.610 & $5,246.120$ & 3.200 & $1,330.000$ & 21.220 & $1,350.000$ & 24.690 & 710.000 & 21.850 & 525.780 \\
\hline \multicolumn{11}{|l|}{ Batako } \\
\hline Test ke -1 & 24.380 & 883.810 & 2.800 & 41.500 & 0.530 & 177.100 & 4.600 & 111.870 & 4.390 & 100.410 \\
\hline Test ke - 2 & 2.530 & 642.120 & 0.600 & 207.300 & 2.650 & 614.200 & 15.960 & 40.950 & 1.670 & 37.960 \\
\hline Test ke -3 & 28.080 & $1,411.030$ & 1.800 & 335.400 & 4.210 & 71.600 & 1.860 & 63.920 & 2.560 & 58.300 \\
\hline Test ke -4 & 13.700 & 869.330 & 1.600 & 286.400 & 3.630 & 143.200 & 3.650 & 71.910 & 2.820 & 64.550 \\
\hline
\end{tabular}

Tabel 3 Kekuatan Batuan Yang Dianggap Mewakili

\begin{tabular}{|c|c|c|c|c|c|c|c|c|c|c|}
\hline \multirow[b]{2}{*}{ Jenis Batuan } & \multicolumn{3}{|c|}{ Kuat Tekan Uniaksial Batu } & \multicolumn{2}{|c|}{$\begin{array}{c}\text { Kuat Tarik Benda Uji Batu } \\
\text { Dengan Cara Tidak Langsung }\end{array}$} & \multicolumn{2}{|c|}{ Kuat Geser Batuan } & \multicolumn{3}{|c|}{$\begin{array}{c}\text { Indeks Kekuatan batu } \\
\text { Dengan Beban Titik }\end{array}$} \\
\hline & $\begin{array}{c}\text { Tegangan Deviator } \\
\text { Puncak } \\
(\mathrm{kg})\end{array}$ & $\begin{array}{c}\text { Modulus } \\
\text { Elastisitas } \\
(\mathrm{kg})\end{array}$ & $\begin{array}{c}\text { Regangan } \\
(\%)\end{array}$ & $\begin{array}{r}\text { Beban } \\
\text { Maks } \\
(\mathrm{kg})\end{array}$ & $\begin{array}{c}\text { Tegangan Tarik } \\
\text { Maks } \\
(\mathrm{kg})\end{array}$ & $\begin{array}{r}\text { Beban } \\
\text { Maks } \\
(\mathrm{kg})\end{array}$ & $\begin{array}{c}\text { Tegangan Geser } \\
\text { Maks } \\
(\mathrm{kg})\end{array}$ & $\begin{array}{l}\text { Beban } \\
\text { Maks } \\
(\mathrm{kg})\end{array}$ & $\begin{array}{c}\text { Indeks Tegangan } \\
\text { Beban Titik } \\
(\mathrm{kg})\end{array}$ & $\begin{array}{c}\text { Tegangan } \\
\text { Tekan } \\
(\mathrm{kg})\end{array}$ \\
\hline Batu Putih Lamongan & 32.5 & 2000 & 1.60 & 220 & 4.80 & 500 & 10.25 & 70 & 2.2 & 70 \\
\hline Batu Putih Bangkalan & 22.5 & 310 & 6.50 & 270 & 3.50 & 180 & 5.00 & 30 & 2.00 & 30 \\
\hline Batu Bata Merah & 11.2 & 31 & 4.10 & 18 & 2.20 & 150 & 4. & 65 & 2.50 & 50 \\
\hline Batu Vulkanik & 170.3 & 5000 & 3.0 & 1300 & 21.00 & 1300 & 22.00 & 720 & 22 & 530 \\
\hline Batako & 21.2 & 1000 & 2.0 & 200 & 2.60 & 170 & 4.50 & 70 & 3.5 & 80 \\
\hline
\end{tabular}

Akan tetapi lebih rendah dibandingkan dengan batu pecah (batu vilkanik) 170.3 $\mathrm{kg} / \mathrm{cm}^{2}$. Untuk kuat tarik batu kumbung Lamongan rata-rata $4.8 \mathrm{~kg} / \mathrm{cm}^{2}$, untuk batu kumbung Bangkalan adalah rata-rata 3.5 $\mathrm{kg} / \mathrm{cm}^{2}$. Mempunyai kekuatan yang lebih tinggi dibandingkan batu bata merah dan batako.

Sedangkan kuat geser batu kumbung Lamongan rata-rata $10.25 \mathrm{~kg} / \mathrm{cm}^{2}$, untuk batu kumbung Bangkalan adalah rata-rata $5.00 \mathrm{~kg} / \mathrm{cm}^{2}$. Mempunyai kekuatan yang lebih tinggi dibandingkan batu bata merah $4.00 \mathrm{~kg} / \mathrm{cm}^{2}$ dan batako $4.50 \mathrm{~kg} / \mathrm{cm}^{2}$. akan tetapi lebuh rendah dibandingkan batu pecah $22.00 \mathrm{~kg} / \mathrm{cm}^{2}$.

\section{KESIMPULAN}

1. Batu putih Lamongan dan Bangkalan mempunyai parameter dasar (kepadatan, berat jenis, kadar air, derajat kejenuhan, porositas dan kadar pori) yang hampir sama, yaitu:
- Kepadatan natural berkisar antara $1.8 \mathrm{gr} / \mathrm{cm}^{3}$.

- Kadar air natural berkisar antara $0.24 \%$.

- Derajat kejenuhan berkisar antara $1.2 \%$.

- Porositas berkisar antara 0.4

- Kadar pori berkisar antara 0.6

2. Batu putih Lamongan mempunyai parameter kekuatan tekan dan geser yang jauh lebih tinggi dari pada batu putih Bangkalan. Kuat tekan dan geser yang jauh lebih tinggi dari pada batu putih Bangkalan. Kuat tekan uniaksial batu putih Lamongan berkisar antara $32.5 \mathrm{~kg} / \mathrm{cm} 2$, sedangkan batu Putih Bangkalan berkisar antara $22.5 \mathrm{~kg} / \mathrm{cm} 2$. Tegangan geser batu putig Lamongan berkisar antara $10,25 \mathrm{~kg} / \mathrm{cm} 2$ sedangkan batu putih Bangkalan berkisar antara $5.00 \mathrm{~kg} / \mathrm{cm} 2$. 
3. Tegangan tarik batu putih Lamongan adalah sekitar $4.80 \mathrm{~kg} / \mathrm{cm} 2$, sedangkan batu putih Bangkalan sekitar 3.50 $\mathrm{kg} / \mathrm{cm} 2$.

4. Batu pecah mempunyai kuat tekan uniaksial sekitar $170.3 \mathrm{~kg} / \mathrm{cm} 2$, tegangan tarik sekitar $21.00 \mathrm{~kg} / \mathrm{cm} 2 \mathrm{dan}$ kuat geser sekitar $22.00 \mathrm{~kg} / \mathrm{cm} 2$. Berarti batu pecah mempunyai parameter kekuatan batuan yang jauh lebih besar dibandingkan dengan jenis batuan yang lain.

\section{DAFTAR ACUAN}

Acuan yang dipakai untuk penulisan artikel ini antara lain:
Das, B.M, 1990, "Principles of Foundation Engineering”, Second Edition, PWS Kent Publishing Company, Boston.

Das, B.M., 1994, “Mekanika Tanah, Prinsipprinsip Rekayasa Geoteknik", Penerbit Erlangga, Jakarta.

Soewarno.1980. Mekanika Teknik, Jilidl,II,III. Gajah Mada Press.

Peraturan Pembebanan Indonesia Untuk Gedung, 1983, Departemen Pekerjaan Umum, Ditjen Cipta Karya, Direktorat Penyelidikan Masalah Bangunan.

Vesis, 1975, "Bearing Capacity of Shallow Foundations", Foundation Engineering Handbook, $1^{\text {st }}$ Edition, New York. 